\title{
BUSCANDO CONEXÕES PARA O DESASTRE: PODER E ESTRATÉGIA NA REDE GLOBAL DE PRODUÇÃO DA VALE
}

\author{
Bruno Milanez ${ }^{1}$, Rodrigo Salles Pereira dos Santos, Maíra Sertã Mansur, Tádzio Peters Coelho \\ Universidade Federal do Rio de Janeiro - UFRJ, Rio de Janeiro, (Brasil) \\ Universidade Federal de Juíz de Fora - UFJF, Minas Gerais, (Brasil) \\ Universidade Federal do Maranhão - UFMA - Maranhão, (Brasil)
}

\section{DETALHES DO ARTIGO}

\section{Histórico do Artigo:}

Artigo Convidado

Disponível online: 01 de agosto de 2019

\section{Editor Científico}

Ilan Avrichir

\section{Palavras-chaves:}

Redes Globais de Produção (RGPs)

Minério de Ferro

Barragem de rejeito

\begin{abstract}
RESUMO
Utilizando o modelo das Redes Globais de Produção, argumenta-se que os fatores que levaram ao rompimento da Barragem I, da Vale S.A., em Brumadinho (MG) em 2019, podem ser interpretados a partir do exercício de poder corporativo, que anulou os sistemas existentes de pesos e contrapesos, e da captura de valor por meio da redução de custos operacionais para garantir o aumento da remuneração aos acionistas, em um contexto de crescente financeirização. $O$ artigo é construído a partir de revisão bibliográfica e análise documental. A construção do argumento se inicia a partir da construção do conceito de estratégia, definida como um repertório de ações coordenadas desempenhadas por um ou mais agentes que envolve o exercício do poder com o objetivo de: (1) aumentar a capacidade de ampliar ou capturar valor; (2) expandir o poder ou reduzir o poder de outros agentes; e/ou (3) modificar condições de enraizamento, próprias e as de outros agentes. Lançando mão dessa definição, em seguida, apresenta-se uma análise de restrições e oportunidades de geração e captura de valor pela Vale e da associação de suas estratégias com um aumento do risco operacional da Barragem I.
\end{abstract}

\section{Introdução}

Nos últimos anos, a análise sobre a atuação de corporações transnacionais (CTNs) avançou significativamente. Nesse contexto, abordagens como as de Cadeia de Valor e Cadeias Globais de Commodities foram usadas como fundamento para a proposição do modelo das Redes Globais de Produção (RGPs). Esse modelo, no entanto, vai além da análise de agentes econômicos (firmas) para também incluir agentes não-econômicos (Estado, sindicatos, organizações não governamentais, etc.), apresentando três categorias principais de análise: valor, poder e enraizamento. Lançando mão desse modelo, foi construído o conceito de estratégia que, aqui, foi utilizado para avaliar as oportunidades e restrições da Vale S.A. (Vale) para gerar, ampliar e capturar valor ao longo de sua cadeia extrativa.

A partir dessa análise, foi identificado um contexto de crescente financeirização da empresa e, consequentemente, um aumento da exigência de captura de valor por parte de seus acionistas e outros agentes financeiros. Por outro lado, condições de enraizamento (material e em rede) foram identificadas como limitadores da capacidade da Vale capturar valor das siderúrgicas chinesas (seus principais clientes). Assim, a estratégia alternativa que restou à empresa teria sido a intensificação da captura de valor pelo lado da produção, por meio da redução de custos operacionais. Tal condição, entretanto, somente se mostrou viável a partir do momento que a empresa lançou mão de estratégias específicas para reduzir os sistemas de pesos e contrapesos existentes no Brasil. A redução significativa desses sistemas de controle sobre a atuação da empresa estaria, então, associada ao surgimento das condições (econômicas, sociais e institucionais) que teriam permitido que ocorresse o rompimento da Barragem I, em Brumadinho, em janeiro de 2019.

\footnotetext{
${ }^{1}$ Contato do autor. E-mail: bruno.milanez@ufjf.edu.br
} 
Para apresentar esse argumento, o presente artigo está organizado em quatro seções, além dessa introdução. Primeiramente é feita uma breve apresentação do modelo das RGPs e, dentro dele, do conceito de estratégia. Em seguida, utilizando esses conceitos, analisa-se a Vale e como ela exerce diferentes formas de poder, para tentar garantir, quando possível, maior captura de valor. Na Seção 3, trata-se especificamente da situação do desastre em Brumadinho e como a tática de redução de custos pode ter repercutido no monitoramento e manutenção preventiva de suas barragens. Por fim, na última seção são apresentadas as considerações finais e principais conclusões do artigo.

\section{Redes Globais de Produção e a perspectiva da estratégia}

\section{A Rede como unidade analítica}

O modelo das RGPs define a globalização econômica como um processo de larga escala que liga a extração de matérias-primas, a produção de bens, a oferta de serviços, o transporte, o consumo, e o descarte de rejeitos. Dessa forma, novos sistemas transnacionais de produção levam à integração funcional de atividades espacialmente dispersas (Coe, Dicken, \& Hess, 2008; Dicken, 2011).

Em termos gerais, o modelo avalia o papel de agentes específicos, que incluem as firmas (bem como seus fornecedores e clientes), Estados, trabalhadores e movimentos sociais.

Com relação aos agentes econômicos, o modelo tem a firma como foco analítico. As corporações constantemente competem para aumentar sua influência de forma a alcançar objetivos econômicos específicos, tais como redução de custos, aumento de receita, crescimento de participação no mercado, entre outros. (Henderson, Dicken, Hess, Coe, \& Yeung, 2002).

Além da firma, o Estado é concebido como o protótipo do agente político; ao mesmo tempo agentes e arranjos institucionais são considerados como elementos-chave (Wilson, 2013). Os agentes sociais, tais como trabalhadores, movimentos sociais e organizações não-governamentais (ONGs) também são incluídos, partindo de uma concepção ampla de agência (Henderson et al., 2002). Sendo assim, os agentes econômicos conduzem estruturas e processos em torno dos quais orbitam uma variedade de outros agentes. Dessa forma, o modelo reconhece que agentes políticos e sociais possuem interfaces complementares e essenciais no condicionamento das atividades econômicas.

Nesse contexto, o modelo das RGPs considera como esses agentes se relacionam a partir de três categorias: enraizamento (social, territorial, em rede e material), poder (corporativo, institucional e coletivo) e valor (criação/extração, ampliação, captura e destruição) (Dicken, 2011; Hess, 2004; Santos \& Milanez, 2015a).

A noção de enraizamento remete às diferentes formas de construção social da economia (Granovetter, 2007), de modo que a abordagem das RGPs criou uma tipologia específica na tentativa de torná-lo operacional. Nela, são acentuados as formas de enraizamento territorial, em rede (Henderson et al., 2002), social (Hess, 2004), e material (Santos \& Milanez, 2015b).

Poder, em termos gerais, é entendido como a capacidade de um agente em influenciar as ações de outros (Gereffi, 1994; Henderson et al., 2002). Dicken (2011) argumenta que relações de poder em uma RGP são desiguais e dependem principalmente do acesso e do controle de ativos relevantes, tais como capital, tecnologia, conhecimento, recursos naturais, entre outros. O modelo das RGPs se baseia em uma tipologia de poder relacionada aos agentes: corporativo, institucional e coletivo (Henderson et al., 2002).

A terceira categoria é o valor, que se baseia tanto na noção marxiana de mais-valia, quanto na perspectiva mais ortodoxa de renda econômica (Henderson et al., 2002; Kaplinsky, 1998). Esta estratégia sugere a necessidade de não apenas se estudar a criação/extração de valor, mas também de entender os processos de sua ampliação e captura. Dicken (2011) ainda propõe a possibilidade de destruição de valor, conceito relevante para o estudo de setores extrativos (Santos \& Milanez, 2015a).

Embora não incorporada à formulação original do modelo, a financeirização constituiria um processo adicional de caracterização do valor, ainda que pouco desenvolvido. Assim, Santos (2011) chama a atenção para a "multiplicação financeira do valor", enquanto Dörry (2016) enfatiza o papel dos intermediários financeiros na geração de rendas econômicas. Ademais, Coe, Lai, and Wójcik (2014) defendem a incorporação das finanças à abordagem, evidenciando essa esfera como dimensão indispensável aos estudos empíricos de RGPs. 


\section{Construindo relações entre valor, poder e enraizamento: o papel das as estratégias nas RGPs}

Apesar de sua riqueza analítica, em seu formato clássico (Henderson et al., 2002; Hess, 2004) o modelo apresenta enraizamento, poder e valor como elementos independentes. Diferentemente, entendemos que existem relações implícitas entre essas três categorias e que agentes disputam os processos relacionados ao valor (em suas dimensões monetária e não-monetária), de modo que seu sucesso depende principalmente das relações de poder, que são influenciadas e definidas pelas condições de enraizamento. Cada grupo de agentes desenvolve um repertório de ações, definido como estratégia², de forma a modificar essas três categorias.

Sendo assim, propomos a incorporação ao modelo das RGPs da noção de estratégia como um repertório de ações coordenadas desempenhadas por um ou mais agentes - em grande medida, coletivos, que envolve o exercício do poder com o objetivo de: (1) aumentar sua capacidade de ampliar ou capturar valor; (2) ampliar seu poder ou reduzir o poder de outros agentes; ou (3) modificar condições de enraizamento, próprias e as de outros agentes.

Dessa forma, o conceito de estratégia é definido a partir de um entendimento amplo e não restrito à perspectiva usual que a limita a "um plano - uma forma de curso de ação conscientemente planejada" Mintzberg (1987, p. 11).

Ao fazer isso, buscamos incluir também pressões práticas e/ou estruturais (Bourdieu, 2005, p. 34). Portanto, partimos do pressuposto que estratégias existem como parte de estruturas mais amplas, determinadas por relações assimétricas entre múltiplos agentes. Nesses termos, "as decisões (dos dominantes, como dos dominados) são somente escolhas entre possíveis definidos (em seus limites) pela estrutura do campo" (Bourdieu, 2005, p. 27). Assim, essa dimensão impõe uma perspectiva

\footnotetext{
2 Em uma revisão da abordagem, Coe and Yeung (2015, pp. 123-124) definem a estratégia como um conjunto de "mecanismos causais" de coordenação de redes de produção centradas na firma, podendo ser tipificada sob as formas de coordenação intra-firma, de controle interfirma, de parceria inter-firma, de barganha extra-firma. No entanto, a medida que os três primeiros tipos se restringem a firmas - se assemelhando ao debate em torno da governança de cadeias de valor (ver Gereffi,
}

essencialmente política (Fligstein, 2002), centrada nas relações de poder, tanto internas quantos externas, entre os agentes dominantes e dominados.

Portanto, em nossa perspectiva, a estratégia é entendida como um "padrão de fluxos de ações" (Mintzberg, 1987, p. 12) ou, como "um curso de ações tomado por um agente ou grupo de agentes" (Anderson, 2003, p. 14). Ao mesmo tempo, uma estratégia pode ser explícita, tendo sido formalmente concebida e documentada, ou implícita, criada de forma tácita. Por fim, um conceito de estratégia deve ainda incluir inações, referentes a qualquer medida que um agente decida "tomar ou não tomar" (Dye, 2013, p. 3).

Do ponto de vista analítico, nos apropriamos e adaptamos o modelo da RGP de forma a criar um modelo operativo. Assim, partindo dos grupos de agentes descritos na literatura (firmas, consumidores, trabalhadores, organizações sociais e Estado), descrevemos seis estratégias distintas: estratégias de mercado, financeiras, institucionais, de relações de trabalho, sociais e territoriais.

\section{A Vale e suas estratégias ${ }^{3}$ \\ Preâmbulo: as condições de enraizamento}

A Vale foi criada em 1942 no contexto da Segunda Guerra Mundial. Naquele momento, os Acordos de Washington tornaram possível uma parceria entre Brasil, Estados Unidos e Inglaterra para a constituição da então Companhia Vale do Rio Doce (CVRD) como empresa estatal para fornecer minério de ferro brasileiro aos Aliados. Como contrapartida, os Acordos viabilizariam o financiamento de uma siderúrgica no Brasil. Assim, a Vale foi constituída para, primordialmente garantir que o mercado internacional tivesse acesso às ricas jazidas de minério de ferro localizadas no Quadrilátero Ferrífero (MG) e, indiretamente, para criar as bases materiais que possibilitassem atender ao projeto de industrialização no país. (Silva, 2004; Triner, 2011).

Humphrey, \& Sturgeon, 2005), e apenas o último incorpora os agentes não econômicos, a proposta reifica a divisão entre os tipos de agentes e assume uma orientação normativa. Por esse motivo, optamos por um conceito mais amplo e que contribua de forma mais rica para debates analíticos, como o proposto no presente trabalho. ${ }^{3}$ Uma discussão mais detalhada sobre o uso do modelo para avaliar as estratégias da Vale S.A. pode ser encontrada em Milanez et al. (2018). 
Ao longo do tempo, o Brasil se tornou um importante player do mercado global de ferro. Nos anos 1960, o país era responsável por quase $7 \%$ das exportações totais do minério; esta participação foi ampliada para $25 \%$ nos anos 1980 , se mantendo no patamar de 30\% a partir da década de 1990 (International Trade Center, 2019; Triner, 2011).

Nos anos 1990, a agenda política neoliberal foi amplamente adotada pelos governos brasileiros, levando à privatização de diversas empresas estatais. A CVRD foi privatizada em 1997, e mudou seu nome para Vale em 2007. No processo de privatização, o controle da empresa foi transferido para o grupo Valepar, formado por fundos de pensão vinculados às empresas estatais, grupos internacionais e grupos financeiros nacionais. Foi ainda mantida certa participação do Estado por meio do Banco Nacional de Desenvolvimento Econômico e Social (BNDES) (Mansur et al., 2016).

Posteriormente, foi iniciado um movimento para reduzir a concentração do controle da Vale, assim como voltado a restringir a participação estatal. A chamada "nova governança corporativa" da Vale foi ratificada em fins de 2017, a partir do processo de conversão das ações preferenciais da companhia em ações ordinárias. Isto criou uma estrutura de propriedade unificada, com vistas à adequação às regras no Novo Mercado da B3; e, finalmente, à incorporação do grupo controlador (Valepar) à estrutura da firma. O objetivo final de tais mudanças seria a transformação da empresa em uma sociedade sem controle definido até 2020 (Santos, 2017).

Em 2017, a Vale apresentava elevada concentração de mercado em termos de minérios comercializados, com especial foco no minério de ferro ${ }^{4}$. Ela também se caracteriza por sua concentração espacial; apesar de possuir operações, escritórios e joint ventures em cerca de 30 países, a Vale centraliza suas atividades no Brasil, onde se encontram 78\% de seus trabalhadores (Vale, 2018e).

O mercado de minério de ferro apresenta uma estrutura oligopólica limitando de modo importante a competição. Em 2015, o mercado transoceânico era controlado por quatro corporações, Vale $(22,5 \%)$,

\footnotetext{
${ }^{4}$ A Vale ainda possui operações envolvendo diferentes minerais como níquel, cobre e carvão. A importância dos minerais ferrosos é decisiva, com ênfase no minério de ferro $(54,5 \%)$ e pelotas $(16,7 \%)$, na composição da receita operacional da companhia. Os metais básicos
}

BHP Billiton (20,1\%), Rio Tinto (19,9\%) e Fortescue $(12,3 \%)$, que respondiam por $74,8 \%$ da oferta mundial (Löf \& Ericsson, 2016, p. 24). A Vale ampliou sua participação em 2016, atingindo 24,0\% de market share (Löf \& Ericsson, 2017, p. 35).

A espacialização das operações da Vale é também desigualmente distribuída. No caso dos minerais ferrosos, sua extração e processamento são quase exclusivamente realizados no Brasil. A corporação regionaliza a extração do ferro em quatro sistemas. O Sistema Norte se localiza no Pará, estando voltado aos mercados asiático e europeu. O Sistemas Sudeste e Sul abrangem o Quadrilátero Ferrífero e atendem tanto siderúrgicas localizadas na região Sudeste, quanto o mercado internacional. O quarto sistema, Centro-Oeste, está localizado no Mato Grosso do Sul, permitindo o escoamento de minério em menor escala pelo rio Paraguai e portos argentinos (Vale, 2018b, pp. 32-34).

Assim, apesar de uma certa diversificação, a produção da Vale e, consequentemente, sua capacidade de extração de valor dependem essencialmente das reservas de minério de ferro que a empresa possui no Brasil. Devido a essa centralidade, a análise estratégica apresentada será focada no segmento de minério de ferro e nas operações no país.

\section{Estratégias de mercado}

A noção de estratégia de mercado diz respeito aos padrões geográficos e/ou setoriais de alocação de recursos; aos padrões tecnológicos; e ao portfólio de ativos e estrutura de comercialização de bens/serviços, a partir do posicionamento da corporação em relação aos seus competidores e aos agentes políticos e sociais (Santos \& Milanez, 2017, p. 13).

O minério de ferro foi o carro-chefe da ampliação da receita durante o boom das commodities (Santos, 2016), embora a concentração neste produto passasse a ser vista como problemática pela corporação, que definiu uma "menor dependência do minério de ferro" como objetivo de médio prazo, se apoiando na "extração de maior valor dos ativos existentes" (Vale, 2018d, p. 2). As tentativas de

responderam por $20,2 \%$ da receita, compreendendo níquel e outros produtos $(13,7 \%)$ e cobre $(6,5 \%)$. O carvão é o terceiro em importância, tendo respondido por 4,6\% da receita em 2017 (Vale, 2018b, p. 2). 
diversificação, entretanto, se mostraram lentas e o ferro se manteve como elemento-chave para a empresa.

A indústria siderúrgica consome todo o minério e pelotas de ferro da Vale, o que explica a dependência de suas receitas dos resultados desse setor e, indiretamente, de dinâmicas industriais e urbanas das economias emergentes. Assim, a China respondeu por 57\% dos embarques em 2017 - a participação da Ásia atingiu $71 \%$-, seguida pela Europa (13\%) e Brasil (9\%) (Vale, 2018b, p. 37).

Nesse contexto, deve-se levar em conta que a estratégia de negociação de preço foi influenciada pela mudança no sistema de precificação do minério de ferro em fins dos anos 2000 (Bhattacharyya \& Deepak, 2012; Ma, 2013; Santos, 2010; Yao, Ma, \& Zhang, 2018). Até então, dois regimes coexistiam de maneira hierarquizada: o regime principal centravase em um "mecanismo de precificação anual fixa" (benchmark) (Bhattacharyya \& Deepak, 2012, p. 71) do minério australiano e brasileiro; e o complementar se baseava no mercado à vista (spot), ocupado pelo minério indiano (Yao et al., 2018, p. 73).

A conversão da China em principal consumidor mundial fez da China Baowu Steel Group Corp. (Baosteel) e da China Iron \& Steel Association (CISA) questionadores do regime de preços. Da mesma forma, "o desenvolvimento do mercado de minério de ferro chinês" (Sukagawa, 2010, p. 56) elevou os preços e induziu a ampliação da oferta de ferro no mercado à vista. Tais mudanças levaram ao abandono do sistema benchmark pelos compradores chineses em 2009 e à introdução de um preço trimestral. Dessa forma, o regime de precificação passou a se constituir de "uma combinação de preço trimestral e ajustamento à vista" (Bhattacharyya \& Deepak, 2012, p. 78).

Assim, a Vale, pressionada pela posição de seus concorrentes, melhor posicionados geograficamente na Austrália e com melhores condições de negociação, teve que seguir as decisões de seu principal mercado na definição do sistema de precificação.

Tais condições passaram a afetar, principalmente, o horizonte temporal da estratégia de mercado da Vale, cada vez mais orientada pelo curto prazo, bem como impor limites a sua capacidade de definir os preços de seus produtos.

\section{Estratégia financeira}

Como consequência da natureza capital-intensiva e dos riscos mercantis vinculados à atividade de extração mineral, empresas mineradoras são confrontadas por problemas relacionados à mobilização e à gestão interna e, principalmente, à obtenção externa de recursos econômicos, dando origem a estratégias financeiras específicas. Tais estratégias respondem fundamentalmente às opções de endividamento e de controle proprietário disponíveis, sendo essas definidas predominantemente por agentes e estruturas externos à corporação e que, portanto, impactam diretamente os processos relacionados à captura de valor e às condições de exercício de poder corporativo (Santos, 2017).

No caso específico da Vale, a política de dividendos e a estratégia financeira se tornaram ainda mais centrais nas operações da empresa. Em 2017, suas despesas de capital atingiram o menor nível desde 2005, totalizando US\$ 3,8 bilhões, uma redução de 29,8\% em relação a 2016 (Vale, 2018b). Tal fato sugere que a dimensão operacional de suas atividades vem perdendo relevância na estrutura de alocação de recursos da empresa diante da dimensão financeira.

O capital social da Vale é composto por cerca de 5,3 bilhões de ações ordinárias. Até 2016, sua composição acionária dava relevo quase exclusivamente ao então grupo controlador. Com as mudanças na governança da empresa foi estabelecido um novo estatuto social e, em dezembro de 2017, a Vale concluiu a sua listagem no segmento de Novo Mercado da B3 (Vale, 2017a).

Após o ingresso da Vale no Novo Mercado, investidores institucionais internacionais como a BlackRock, Inc e a Capital Research and Management Company (CRMC) assumiram maior destaque. Sua participação acionária ainda não indica poder decisório na empresa, mas impressiona por seu crescimento em comparação com o ano de 2016. Nessa nova estrutura, o principal acionista continuou sendo a Litel Participações (37\%), seguida da CRMC (15\%), BNDESPar (15\%), Bradespar (12\%), BlackRock, Inc. (11\%) e Mitsui (10\%) (Vale, 2018b, p. 115). Nesse contexto, o aumento da participação de fundos de investimento na composição acionária tende por aumentar a pressão pelo aumento do retorno aos acionistas no curto prazo. 
Em anos recentes, as principais fontes de recursos da corporação têm sido o fluxo de caixa operacional e os empréstimos, complementados pela alienação de ativos (Vale, 2018b, p. 103).

Em primeiro lugar, o fluxo de caixa da companhia é estruturalmente dependente dos preços do minério de ferro, que vêm apresentando comportamento mais volátil recentemente (Market index, 2018). A segunda maior fonte de obtenção de recursos externos da companhia são os empréstimos. Em 2017, a Vale tomou emprestado o valor de US\$ 1,5 bilhão. Dessa forma, a Vale emitiu títulos (bonds) por meio de sua subsidiária integral Vale Overseas Ltd. no valor de US\$1,0 bilhão, com vencimento em 2026 (Vale, 2018b, p. 103). Embora de forma modesta, a Vale continua a se apoiar no crédito público como forma de financiamento de suas operações. Em 2017, a empresa manteve acordos referentes a linhas de crédito em disponibilidade junto ao BNDES (Vale, 2018b, p. 105). Em terceiro lugar, as debêntures (títulos de dívida) são outro importante instrumento de captação de recursos pela empresa. Esse mecanismo financeiro propicia captação mais difusa de recursos, sendo as dívidas contabilizadas como de longo prazo e com juros baixos (Wainberg, 2017).

Em síntese, apesar dos empréstimos públicos, isoladamente, serem o principal mecanismo de obtenção de recursos externos da Vale $(48,4 \%)$, se forem somados o crédito privado $(41,6 \%)$ e a emissão de títulos $(9,8 \%)$, os agentes privados vem assumindo maior importância na estrutura de financiamento da empresa. Assim, a Vale parece estar adaptando suas estratégias para obtenção de recursos financeiros, diminuindo a importância do governo na sua estrutura de governança e aumentando a participação de agentes financeiros, como os fundos de investimento, como forma de facilitar o acesso a recursos externos.

Nesses termos, agentes privados vêm se tornando os principais financiadores da Vale. Como consequência, confirmando essa tendência, será a demanda de tais agentes que ela deverá priorizar para garantir a manutenção de suas operações. Não por acaso, em 2017 ela aplicou uma política de corte sistemático dos custos de produção, disciplina nos investimentos e foco no seu core business, com o objetivo de reduzir dívidas e aumentar sua capacidade de pagamento de dividendos. Nesse cenário, a empresa fez um esforço sistemático para aumentar a remuneração de seus acionistas. Apesar do prejuízo líquido de US\$12,6 bilhões em 2015, o total pago aos acionistas naquele ano foi US\$ 1,5 bilhão. Em 2016, o pagamento foi consideravelmente menor (US\$ 250 milhões), podendo essa redução ser associada aos aportes feitos à Samarco (joint venture da Vale e da BHP Billiton) devido aos gastos associados ao rompimento da barragem de Fundão, no ano anterior. $O$ pagamento aos acionistas, porém, se recuperou rapidamente, crescendo sistematicamente em 2017 (US\$ 1,4 bilhão) e 2018 (US\$ 3,3 bilhões) (Vale, 2019b). Assim, o retorno aos acionistas se tornou um dos elementos centrais da estratégia financeira da corporação nos anos recentes (Vale, 2018b, p. 121).

\section{Estratégia institucional}

Como estratégia institucional, definimos as iniciativas das corporações que envolvem o exercício de seu poder direcionado ao Estado e aos agentes públicos. Assim, conceituamos a estratégia institucional como o conjunto de ações utilizadas na tentativa de "exercer uma influência regulatória forte e consistente" (Szablowski, 2007, p. 8) sobre os agentes políticos.

A literatura lista uma variedade de táticas adotadas pelas corporações na tentativa de influenciar agentes públicos. Fuchs (2013) organiza essas táticas em três dimensões. Primeiramente, a autora descreve a perspectiva estruturalista material, associada ao poder econômico das empresas. Em segundo lugar, ela menciona a dimensão estruturalista ideacional, baseada na criação de símbolos e narrativas pelas empresas. Por fim, a autora trata da perspectiva instrumental, que focaliza a influência direta das corporações sobre os agentes do Estado, por meio de lobby, financiamento de campanha e porta giratória.

Do ponto de vista das táticas de cunho estruturalista material, tais práticas são mais visíveis na esfera municipal, uma vez que a Vale possui um faturamento muito superior à receita dos municípios onde opera, o que the concede poder econômico desproporcional. Para a implementação de tais táticas, o instrumento mais comum é a instituição de parcerias e o financiamento de obras públicas.

Quanto à sua atuação específica em Brumadinho, um elemento a ser considerado é o tamanho da empresa no município. Assim, enquanto o total das receitas brutas realizadas pela Prefeitura de 
Brumadinho em 2017 foi de R\$ 175,5 milhões, no mesmo ano, o total das operações conjuntas da Vale e sua subsidiária MBR no município foi de R\$1.162,0 milhões, ou seja, mais de seis vezes as receitas da prefeitura. Um segundo elemento seria seu papel no orçamento público local. Em 2018, a receita municipal de Brumadinho oriunda da Compensação Financeira pela Exploração Mineral (CFEM) paga pela Vale foi de R\$16,5 milhões, o que corresponderia a $26,4 \%$ da CFEM total do município e $10,5 \%$ de suas receitas correntes (ANM, 2018; SICONFI, 2018).

Este poder material teria um impacto direto no fortalecimento do poder corporativo no âmbito ideacional. À medida que a empresa realiza uma série de obras públicas, ela passa a ser vista como uma benfeitora, o que diminui consideravelmente a contestação social e a pressão sobre a empresa. Por exemplo, em pesquisa realizada na região de Itabira, onde a Vale foi fundada:

[o] enfrentamento mesmo ficou na mão da política que sempre circulou ao redor da Vale do Rio Doce né [...] que a Vale...ela comprava as consciências por aí e muita gente, muita gente, como não tinha coragem de enfrentamento né, sofreu, muita gente morreu por causa disso [...] (Entrevista com liderança comunitária de Santa Maria de Itabira (MG), realizada em 2015 por B. Milanez e R. S. P. Santos).

Situação semelhante parecia ocorrer em Brumadinho, antes do rompimento da Barragem I. Apesar da existência de um movimento ativo de contestação social à atuação da empresa desde 2011, esse permaneceu restrito à vizinhança das operações da Vale, motivado principalmente por questões associadas à expansão das operações e aos impactos sobre a água (Campos, 2015) sem, aparentemente, ser amplamente incorporado pela população urbana.

Do ponto de vista instrumental, o poder econômico da Vale e suas condições de enraizamento como ex-empresa estatal parecem ter Ihe fornecido um nível de poder particularmente elevado na relação com os agentes públicos, tanto na esfera federal, quanto na estadual. Isso pode ser percebido a partir do financiamento de campanha, do acesso privilegiado a esferas de decisão e do uso da "porta giratória".

O financiamento de campanhas eleitorais foi uma importante estratégia da Vale até a sua proibição em 2015. Nas eleições de 2012 e 2014 a Vale foi a principal mineradora financiadora de campanhas, contribuindo, respectivamente com $\mathrm{R} \$ 30$ milhões e R\$ 22,7 milhões (Oliveira, 2013, 2015). Na esfera federal, na eleição de 2014, a candidatura de Dilma Rousseff recebeu diretamente $R \$ 12$ milhões das empresas do grupo Vale, enquanto a campanha de Aécio Neves foi apoiada com R\$ 3 milhões. Já no nível estadual o Governador de Minas Gerais, Fernando Pimentel (PT), recebeu um total de $R \$ 3,1$ milhões (Coelho, Milanez, \& Pinto, 2016).

Associado a isso, a Vale passou a ter amplo acesso aos órgãos decisórios. Por exemplo, durante a discussão do Plano Nacional de Mineração 2030, em 2010, o Ministério de Minas e Energia (MME) organizou oito oficinas principalmente com organizações governamentais, a Vale participou de quatro dessas oficinas (MME, 2011). Da mesma forma, sugestões feitas pela Vale a servidores do estado de Minas Gerais em oficinas realizadas em 2014 com relação à simplificação do licenciamento ambiental foram incorporadas na revisão da legislação posteriormente (Angelo, 2019).

Uma terceira prática associada à perspectiva instrumental é a porta giratória entre corporações e agências governamentais. Por exemplo, quando Vicente Humberto Lôbo Cruz (ex-diretor da Vale Fertilizantes) foi nomeado pelo governo Temer para o cargo de Secretário de Geologia, Mineração e Transformação Mineral no MME, em 2016, ele indicou ex-diretores ou consultores da Vale para todos os quatro cargos de diretoria de sua secretaria (Milanez, Coelho, \& Wanderley, 2017).

Dessa forma, é possível identificar a diversidade de táticas utilizadas pela Vale em sua relação com o Estado. O poder que ela exerce tanto no nível nacional, quanto nos níveis regional e local, the permitiria um acesso diferenciado ao processo de decisão. Esse acesso tende a possibilitar condições mais favoráveis de captura de valor, particularmente do ponto de vista da produção. Por outro lado, ele acaba por enfraquecer as estruturas de monitoramento e controle externos à empresa que deveriam, entre outras coisas, garantir a segurança de suas operações.

\section{Estratégia de relações de trabalho}

Dentre as diferentes formas de criação, ampliação e captura de valor pelas corporações, as relações de trabalho e sindicais são determinantes; por isso, as relações entre empresa e os trabalhadores devem 
ocupar espaço central em análises de RGPs (Ramalho \& Santos, 2018).

Os custos trabalhistas, salários e condições de trabalho de maneira geral são objetos da estratégia das empresas mineradoras de captura de valor. Entretanto, a agência não se restringe apenas às empresas mineradoras e ao Estado, e, por se tratar de uma análise de rede, inclui também os trabalhadores e os sindicatos. Estes agentes tentam influenciar os processos decisórios ao longo das RGPs, se relacionando com os vários âmbitos do próprio Estado, adotando estratégias específicas e formulando resistências.

Do ponto de vista da atuação da Vale, possuem grande relevância as estratégias relacionadas a formas de contratação e demissão. Nas relações de trabalho, destacamos como principal tática, a utilização de formas de contratação terceirizadas e quarteirizadas.

Apesar de não ser uma exclusividade da Vale, a terceirização na empresa abrange boa parte das relações de trabalho e é central para a ampliação da criação de valor. Em 2015, do total de 166,3 mil trabalhadores, 92,2 mil eram terceirizados, ou $55,4 \%$ do total. Em 2018, o número caiu para 54,6 mil terceirizados num total de 124,9 mil, ou $43,7 \%$ do total (Vale, 2018e, 2019d) não tendo variado em termos relativos entre 2017 e 2018, mas permanecendo ainda bastante expressivo ${ }^{5}$.

Embora a Vale não disponibilize dados a respeito da alocação de trabalhadores diretos e terceiros em suas operações, esse último contingente assume importância desproporcional nas atividades de manutenção de infraestruturas (incluindo barragens), como sugerem os dados sobre os vínculos das vítimas fatais no desastre provocado pela Samarco em Mariana (ver Mansur et al., 2016). Assim, o padrão de condições de trabalho na Vale, especificamente no que diz respeito à saúde e à segurança, focaliza a redução de gastos, em particular nos setores de apoio. Por exemplo, em Itabirito (MG), a Superintendência Regional do Trabalho e Emprego (SRTE) autuou a empresa, tendo identificado 309 motoristas vinculados à subcontratada Ouro Verde em "situação análoga à

\footnotetext{
${ }^{5}$ A redução recente, absoluta e relativa, do número de terceirizados é explicada pela desmobilização de mão de obra gerada pela conclusão de projetos, em especial do Projeto S11D, no Pará, uma vez que sua utilização é mais
}

escravidão" (Valor Econômico, 2015; Xavier \& Vieira, 2017).

No que diz respeito às relações sindicais, a gestão do relacionamento com os organismos de representação dos trabalhadores também se mostra como uma estratégia importante. Nesse sentido, a Vale tem buscado, historicamente, aproximar as direções sindicais de seus interesses, as subordinando de diferentes formas. Uma das principais táticas têm sido o apoio à formação de chapas que disputem a direção dos sindicatos, além da demissão de funcionários que se disponham a formar chapas de oposição à Vale e da inviabilização das mesmas (Aguiar, 2019; Bertollo, 2017).

O enfraquecimento da organização dos trabalhadores pode ser associado como importante fator que possibilitou o rompimento da Barragem I. Os sindicatos seriam um dos principais elementos de resistência dos trabalhadores contra o processo de precarização das condições de segurança. Entretanto, essa tarefa se mostra cada vez mais desafiante. Um sindicato fortalecido seria capaz de questionar a empresa em relação às condições de trabalho, incluindo a construção, manutenção e o monitoramento de barragens. Porém, à medida que os sindicatos são enfraquecidos, menor é a capacidade dos trabalhadores exercerem pressão e garantirem a manutenção das condições de saúde e segurança.

\section{Estratégia social}

Quando abordamos especificamente as estratégias sociais corporativas, referimo-nos "à influência exercida pelas corporações sobre os padrões emocionais, cognitivos e de agência da sociedade civil, apreendida igualmente a partir de escalas múltiplas e interativas" (Santos \& Milanez, 2015a, p. 12). Nessa perspectiva, as práticas de Responsabilidade Social Corporativa (RSC) possuem um caráter extremamente importante.

Há indicativos na literatura empresarial sobre a relação entre programas de RSC e a expansão do poder corporativo da Vale no território (Giffoni Pinto, 2015). Em seu relatório para a Comissão de Valores Mobiliários dos EUA, a empresa esclarece aos acionistas que está sujeita à contestação social de

intensa em obras de construção, ampliação e reforma de infraestrutura. Assim, a redução da participação de mão de obra terceirizada foi consequência da própria precariedade dessa forma de contratação. 
diversos grupos e que esta situação pode, eventualmente, ocasionar perdas à empresa (Vale, 2017a, p. 5).

No entanto, a estratégia social não se resume aos discursos e práticas de RSC. As táticas que compõem tal estratégia são quaisquer ações previamente delineadas que possam gerenciar a contestação social de grupos críticos à atuação empresarial e garantir o apoio do Estado, em todas as esferas, e das comunidades locais com vistas à "melhoria no acesso a recursos em ambientes que sejam cada vez mais desafiadores ou remotos" (ESMAP, Mundial, \& ICMM, 2005, p. 14). Essas táticas podem ser constituídas por mecanismos coercitivos, violentos e/ou de convencimento.

Por exemplo, os mecanismos jurídicos utilizados pela empresa não buscam necessariamente a sua legitimidade, mas a sua segurança operacional. "Se a interrupção for provocada por interdições relacionadas a conflitos sociais, diversas áreas da Vale - Relações com Comunidade, Segurança Empresarial, Jurídico e Comunicação, entre outras - são acionadas, em conformidade com o Plano de Atendimento à Interdição Ferroviária" (Vale, 2018e, p. 130). Em muitos casos o instrumento jurídico de interdito proibitório é utilizado ao longo das estruturas logísticas da empresa, seja no Sistema Norte, seja no Sistema Sudeste, para prevenir as ocupações e evitar perdas econômicas. Segundo dados da Agência Pública, de 2013 a 2017 a Vale utilizou o interdito proibitório em 25 casos, apenas na Estrada de Ferro Carajás (Domenici, 2017).

Em resumo, podemos identificar uma ampla gama de táticas utilizadas pela Vale na relação com a sociedade. Assim, poderíamos dizer que as ações de RSC pretendem garantir a reputação da empresa, tanto no plano local quanto nos nacional e internacional. 0 alvo destas ações são, majoritariamente, comunidades do entorno das operações, mas não apenas. Essa atuação organizada, de certa forma, ajuda a explicar a baixa taxa de contestação enfrentada pela empresa em Brumadinho, antes do rompimento da Barragem I.

Por outro lado, as táticas judiciais e policiais, embora estejam no escopo da estratégia social, não são voltadas para a imagem da empresa, apresentando uma face mais hostil e geralmente são utilizadas contra os movimentos sociais e moradores que resistem sistematicamente a determinadas práticas da empresa. Embora esteja além do escopo desse trabalho, pesquisa futura será necessária para avaliar até que ponto tais estratégias podem ser adotadas para lidar com a crítica que eventualmente venha a surgir localmente, no caso do não atendimento às demandas das pessoas atingidas pelo rompimento da barragem.

\section{Estratégia territorial}

A noção de estratégia territorial consiste em ações voltadas ao controle do espaço, dos recursos, dos bens e de pessoas nos territórios e redes nos quais as empresas atuam, interagindo com distintos agentes e em múltiplas escalas. Em outras palavras, a estratégia territorial realiza-se mediante a ação direta e indireta das corporações extrativas no espaço com o objetivo de acesso, controle, ampliação e reposição constante e segura de sua base de bens minerais, estando voltadas a assegurar e expandir os processos de captura de valor e para garantir que a circulação de minérios ocorra sem constrangimentos. Sistematizamos a estratégia territorial em controle e ordenamento de fluxos, domínio de áreas e recursos, planejamento e concepção de espaço, e deslocamento político e de capital.

O controle e o ordenamento de fluxos são estratégias para controlar superfícies, linhas e pontos por meio da gestão e do controle do espaço. A atuação ocorre tanto no sentido de dar fluidez ou de criar restrições aos fluxos de pessoas e mercadorias no território corporativo (Rehner, 2012; Silveira, 2007). Para assegurar que os fluxos ocorram sem constrangimentos, a Vale emprega também táticas de controle de acesso às ferrovias e outras infraestruturas de circulação, por exemplo, câmeras de vigilância, muros, placas com avisos proibitivos, cercas e portões em vias de acessos (Wanderley, 2012). Em pesquisa de campo sobre a qualidade da água do Rio Paraopeba realizada logo após o rompimento da Barragem I, foi verificado que havia pontos estratégicos de acesso ao rio controlados por empresas atuando em nome da Vale. Funcionários contratados chegaram a restringir a livre atuação de pesquisadores na realização do trabalho de coleta de material, além de manter vigilância ostensiva durante a realização de suas atividades de pesquisa (Felippe, 2019).

Com relação ao domínio de áreas e de recursos, deve-se levar em conta que a distribuição das reservas minerais ocorre de maneira desigual no espaço conforme a formação geológica. Por consequência, as corporações extrativas passam a 
empregar táticas voltadas para a apropriação de terras, controle de títulos minerários, acesso aos direitos e privilégios de usos de determinadas áreas. Em vista disso, uma das táticas praticadas pela Vale é a de domínio da terra por meio da compra legal ou ilegal, da grilagem, desapropriação e do deslocamento compulsório nas áreas de servidão (Bedinelli, 2016; INESC, 2017). Novamente, ações dessa natureza foram identificadas na negociação do pagamento da indenização a moradores atingidos pelo rompimento da Barragem I. Nos acordos elaborados pela Vale, uma das condições seria que os moradores, para receber as indenizações, deveriam transferir para a Vale os direitos referentes às suas propriedades. Entretanto, os moradores não eram informados no momento da assinatura de que a Vale já possuía o direito minerário referente ao subsolo da região (Possato, Zuba, \& Andrade, 2019).

Por fim, os deslocamentos políticos de escala, e por consequência do poder, e os deslocamentos espaciais do capital são táticas recorrentes no sentido de aumentar o poder corporativo, ou diminuir o poder de outros agentes territoriais, e capturar mais valor. O objetivo dos deslocamentos de maneira geral é reorganizar o território-rede e a escalaridade das ações das corporações mineradoras, permitindo maior fluidez do capital e da ação política. O reescalonamento do poder consiste em uma tática contida no que Cox (1998) chamou de política de escala. Os atores com maior mobilidade saltam entre escalas e possuem capacidade de criação ou redefinição de escalas, o que não impede que os com menor possibilidade de deslocamento escalar não o façam. Um mecanismo tático do escalonamento do poder pode ser constituído pela formação de novas escalas de gestão do território, como foi o caso da área de atuação da fundação Renova, gerida pela Vale e BHP Billiton, após o rompimento da barragem em Mariana (União et al., 2016), que se constitui de uma nova escala infranacional, e supraestadual, para a qual foi constituída uma estrutura de governança específica, relativamente independente dos poderes associados aos níveis federativos.

Nesse sentido, deve-se levar em consideração que as estratégias territoriais possuem uma forte componente de exercício de poder. Embora seja mais comum a identificação de tais estratégias em relação a comunidades, elas podem ser utilizadas em situações envolvendo tanto Estado, quanto outras empresas. Mais do que gerar ou capturar valor diretamente, as estratégias territoriais atuam principalmente nas condições de enraizamento, seja material, seja territorial, modificando condições de atuação tanto da corporação quanto dos agentes com os quais ela se relaciona.

\section{Algumas reflexões sobre as estratégias da Vale}

A partir da análise das estratégias da Vale e da sua (não) capacidade de exercício de poder, identificamos que ela atua como um elemento de transferência e conexão entre processos internacionais e dinâmicas domésticas. Assim, ao atuar em um mercado globalizado, altamente concentrado, e cada vez mais financeirizado, a empresa tem perdido poder na esfera internacional e, consequentemente, sua capacidade de capturar valor pelo lado da receita. Como forma de compensar essa perda e de sustentar sua rentabilidade, ela se volta para práticas cada vez mais intensas de extração/captura de valor a partir das operações extrativas e da busca constante de redução de custos operacionais.

Esse diagnóstico pode ser identificado a partir da avaliação da posição da Vale nos mercados de minérios em que opera, fortemente dependente do minério de ferro e de suas operações no Brasil. O mercado de ferro, em particular, vem mostrando tendência de redução no faturamento, principalmente associado ao surgimento de novos concorrentes (em especial a Fortescue) e de expansão significativa das operações na Austrália, com a consequente redução de custos logísticos, quando comparada às atividades no Brasil. Assim, políticas de valorização de produto - por exemplo através do lançamento dos Brazilian Blend Fines, BRBF -, ou tentativas de elevação de market share no setor de minério de ferro mostram resultados bastante limitados. Ao mesmo temo, as tentativas da Vale de diversificação de mercados, com aumento da participação dos metais básicos, têm se mostrado insuficientes.

Da mesma forma, a empresa passou a enfrentar esse cenário desfavorável ao mesmo tempo em que concluiu o processo de transformação de "empresa estatal" em uma "true corporation". Se por um lado, ela diminuiu a influência do Estado em suas decisões, por outro, passou a se vincular mais fortemente ao mercado global de capitais como fonte de recursos externos. Esse mercado vem se caracterizando pelo aumento da participação de fundos de investimento e ampliando sua influência sobre a estrutura organizacional da Vale. De forma geral, ele pressiona 
de forma crescente a empresa por resultados de curto prazo.

Para atender a tais exigências, a Vale parece possuir uma maior margem de manobra no Brasil, particularmente por sua capacidade de exercício poder nas escalas nacional, regional e local, que se reflete em uma disposição privilegiada de influenciar decisões governamentais, na redução da capacidade de mobilização dos trabalhadores e na influência sobre parte da opinião pública. Essa capacidade garante à empresa condições favoráveis de enraizamento territorial e social no país.

Dada essa situação privilegiada, percebe-se uma busca da manutenção da rentabilidade (e da capacidade de transferência de valor aos acionistas) pela redução de custos operacionais. Em parte, esses objetivos dependem da criação/extração de valor a partir da intensificação da exploração dos trabalhadores, seja pela terceirização, seja pela precarização de suas condições de trabalho, ou mesmo, da redução do investimento em saúde e segurança.

O aprofundamento desse padrão de comportamento, porém, se mostra altamente perigoso em uma atividade de elevado risco, como a extração mineral.

Dessa forma, valendo-se de seu poder em múltiplas escalas, na esfera nacional, a Vale anulou os sistemas de pesos e contrapeses existente e, mesmo após o rompimento da barragem de Fundão, pôde atuar sem que alarmes ou sistemas efetivos de alerta fossem instalados. Assim, a análise sugere que a busca pelo aumento da captura de valor anulou os sistemas internos e externos de monitoramento e controle da atuação da empresa, o que criou as condições para o desastre associado ao rompimento da Barragem I, conforme discutido a seguir.

\section{O Desastre em Brumadinho a partir de uma perspectiva das $\mathrm{RGPS}^{6}$}

\section{Comportamento recente dos gastos operacionais e dos investimentos em segurança}

A partir da análise apresentada na seção anterior, defende-se a hipótese de que que a pressão exercida

\footnotetext{
${ }^{6}$ Uma discussão mais profunda sobre fatores econômicos e institucionais associados ao rompimento da Barragem I pode ser encontrada em Milanez et al. (2019).

7 O Complexo Paraopeba II é integrado pelas minas da Jangada e Córrego do Feijão. Já em 2008, a Vale
}

por acionistas em um contexto cada vez mais financeirizado, aliada à dificuldade de aumento da receita devido à concorrência, levou a Vale a buscar uma redução constante de custos operacionais em sua produção. Esse esforço parece ter sido particularmente intenso no Brasil, onde a empresa concentra sua produção e, como também discutido anteriormente, seu poder. Como parte desse esforço teria havido uma redução nos investimentos em saúde e segurança das operações, o que viria a aumentar o risco das atividades da Vale e, possivelmente, a chance de desastres, como o que ocorreu em Brumadinho.

A Vale apenas divulga suas despesas e gastos de forma agregada, o que limita a verificação de tal hipótese. Para tanto, porém, segue-se a seguinte linha de argumento. Primeiro são apresentados os dados gerais da empresa e do setor de ferrosos para custos operacionais e investimento em segurança, respectivamente. Em seguida, é discutida a situação operacional das barragens do Complexo Paraopeba II $^{7}$. Assim, a partir das informações compiladas argumenta-se que a Vale, apesar de conhecer os problemas estruturais da Barragem I, não vinha realizando os devidos investimentos em manutenção preventiva e corretiva de suas barragens de forma geral.

Conforme mencionado na Seção 0, no contexto recente de financeirização, a Vale vinha fazendo um esforço consistente para ampliar a remuneração de seus acionistas. Dessa forma, os dados disponibilizados pela empresa mostram que o total pago aos acionistas aumentou mais de $100 \%$ entre 2015 e $2018^{8}$. No último ano analisado, o pagamento alcançou o patamar de $9,1 \%$ das receitas operacionais líquidas, o percentual mais alto dos últimos quatro anos (Vale, 2019b).

Ainda, se analisarmos o preço do minério de ferro durante esse intervalo de tempo, o acréscimo de seu preço médio ficou no patamar de 25\% (World Bank, 2019). Da mesma forma, a quantidade de minério de ferro exportado pelo Brasil cresceu apenas 6\% durante o período analisado (International Trade Center, 2019). Portanto, o aumento da remuneração dos acionistas não parece ser explicado

beneficiava conjuntamente o minério das duas cavas como forma de otimizar a estrutura existente e reduzir custos operacionais.

${ }^{8}$ Este consiste no total pago aos acionistas tanto na forma de dividendos, quanto na de juros sobre o capital próprio. 
exclusivamente por uma elevação do preço do ferro ou da demanda por ele.

Por outro lado, como ilustrado na Tabela 1, ao longo desses anos, a Vale parece ter feito um esforço permanente para contenção de seus custos operacionais. Enquanto a receita operacional cresceu $56 \%$, o custo do produto vendido aumentou apenas 18\%. Dessa forma, a participação dos custos dos produtos caiu de $80,2 \%$ para $60,4 \%$ da receita operacional líquida ao longo desse período, liberando maior valor para ser transferido aos acionistas.

Tabela 1: Custo dos produtos vendidos e receita operacional líquida da Vale (2015-2018)

\begin{tabular}{|c|c|c|c|}
\hline Período & $\begin{array}{c}\text { Custo de produtos } \\
\text { vendidos } \\
\text { (US\$ milhões) }\end{array}$ & $\begin{array}{c}\text { Receita operacional líquida } \\
\text { (US\$ milhões) }\end{array}$ & $\begin{array}{c}\text { Custo operacional / receita } \\
\text { operacional (\%) }\end{array}$ \\
\hline 2015 & 18.751 & 23.384 & 80,2 \\
\hline 2016 & 17.650 & 27.488 & 64,2 \\
\hline 2017 & 21.039 & 33.967 & 61,9 \\
\hline 2018 & 22.109 & 36.575 & 60,4 \\
\hline
\end{tabular}

Fonte: Adaptado a partir de Vale (2019b).

Para além dos gastos gerais, cabe ainda avaliar o comportamento do setor de minerais ferrosos da Vale. Conforme apresentado no

Gráfico 1, a produção física de minerais ferrosos cresceu de forma constante entre 2015 e 2018, o que sugeriria uma ampliação ou intensificação de suas operações. Ao mesmo tempo, a receita de vendas líquida da empresa nesse segmento foi ampliada em quase $70 \%$ no mesmo intervalo. Ainda com base nos dados disponibilizados pela empresa, apesar do rompimento da barragem de Fundão em 2015, os investimentos estimados na manutenção das operações de saúde e segurança passaram por cortes significativos no intervalo. Tendo o ano de 2015 como referência, os valores nos anos seguintes foram equivalentes a $52 \%$ (2016), 30\% (2017) e 60\% (2018) (Vale, 2015a, 2016a, 2017b, 2018c).

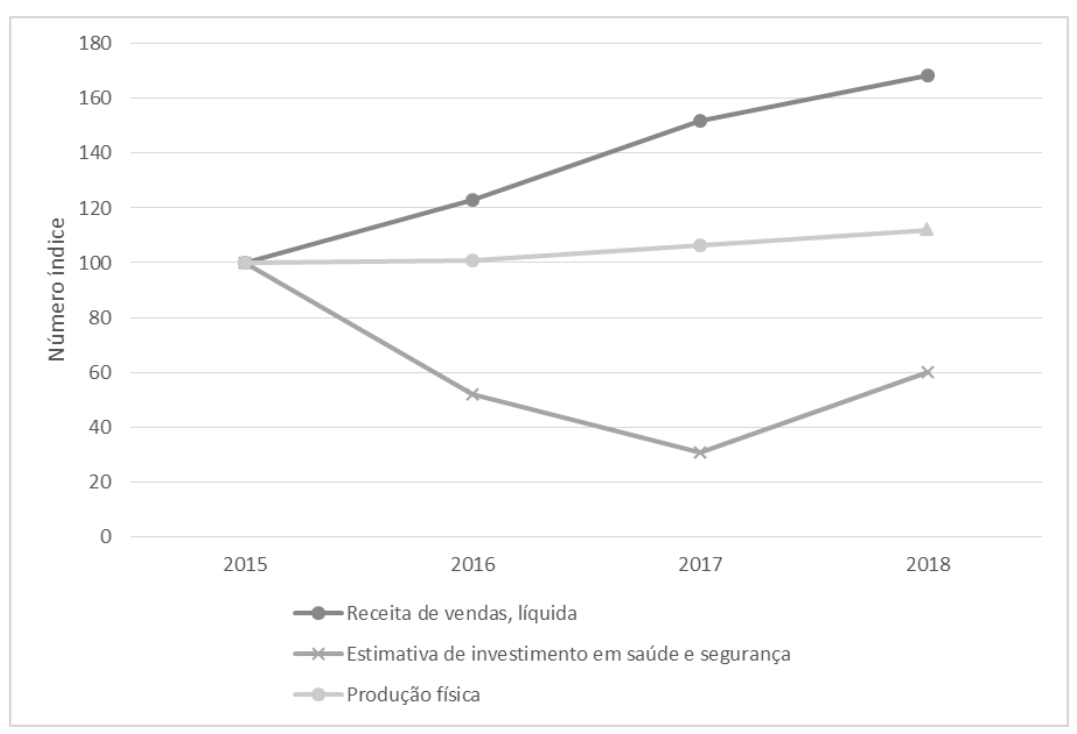

Gráfico 1: Receita de vendas, produção física e estimativa de investimento em saúde e segurança no segmento de minerais ferrosos da Vale

Fonte: Adaptado a partir de Vale (2015a, 2016a, 2017b, 2017c, 2018a, 2018c, 2019a, 2019c).

Esses dados sugerem que, ao menos no segmento de minerais ferrosos, os investimentos em saúde e segurança não acompanharam nem o aumento das receitas, nem o crescimento da produção física. Como a Vale não disponibilizou os dados de investimento em segurança no Complexo Paraopeba
II, não é possível afirmar até que ponto houve aumento ou redução de gastos em segurança especificamente nas operações em Brumadinho. Entretanto, conforme discutido na próxima seção, há evidências que apontam que, apesar de problemas estruturais identificados na Barragem I, a Vale não 
vinha investindo recursos suficientes em atividades de monitoramento ou manutenção preventiva de suas barragens.

\section{O rompimento da Barragem I por uma perspectiva econômica}

Quando houve o rompimento da barragem de Fundão, de propriedade da mineradora Samarco, um importante debate se formou para tentar compreender até que ponto aspectos econômicos favoreceriam a compreensão do desastre. Em grande parte, essa discussão seguia a proposta de Davies and Martin (2009), que propunham ser possível verificar uma relação entre a oscilação de preço dos minérios e a probabilidade de rompimento de barragens de rejeito, de forma que desastres dessa natureza tenderiam a ser mais prováveis nos momentos de pós-boom. Em grande parte, as hipóteses apresentadas pelos autores ajudaram a explicar o rompimento da barragem de Fundão, cujo histórico de construção e operação eram muito semelhantes aqueles identificados no modelo proposto Davies and Martin (2009), como demonstrado por Santos and Wanderley (2016).

Por outro lado, o mesmo modelo, em uma primeira análise, não pareceu totalmente aplicável ao caso da Barragem I, da Vale. Diferente de Fundão, a Barragem I era uma barragem antiga que havia sido desativada em 2016, ou seja, três anos antes de seu rompimento.

Nesse sentido, a discussão proposta por Bowker and Chambers (2017) se mostrou mais adequada para se construir uma explicação econômica do rompimento da Barragem I. O trabalho desses autores se baseia em estatísticas e relações identificadas em um grande banco de dados sobre rompimentos de barragens ao redor do mundo. Uma de suas conclusões é que existe uma correlação entre a ocorrência de falhas severas de barragens e o teor de pureza dos minérios extraídos. Essa correlação teria se fortalecido especialmente após o boom de preços dos anos 2000. Os autores esclarecem que isso se explicaria tanto pelo fato de minas com teores mais baixos de minérios estarem associadas a barragens de rejeito proporcionalmente maiores, quanto por elas serem economicamente menos rentáveis, obrigando as empresas a trabalharem com patamares de custo mais baixos, o que levaria a uma redução dos gastos em segurança e, consequentemente, aumento da chance de rompimentos. Assim, eles indicam que a continuidade da operação em tais condições impediria a gestão das barragens de rejeito de acordo com as melhores técnicas disponíveis.

Os dados divulgados sobre a situação do Complexo Paraopeba II sugerem uma forte semelhança entre seu contexto de operação e o cenário traçado por Bowker and Chambers (2017).

A mina Córrego do Feijão começou a operar em 1923 e a mina da Jangada iniciou suas operações em 1974. Em 2010, a expectativa era que a Cava Córrego do Feijão se exaurisse em 2014 e que a cava da Jangada encerrasse suas atividades em 2018 (Vale, 2011). No plano de mineração para os anos 20122017, a relação entre estéril (material sem valor para a mineradora) e minério bruto que seria produzido pelo complexo variava entre 1,62 e 2,38 (Nicho Engenheiros Consultores Ltda., 2014), uma relação considerada alta para a mineração de ferro. Uma elevada relação de produção de estéril significaria gastos com movimentação de material dentro da mina, além dos custos com a construção, operação e manutenção das pilhas de estéril. Assim, as informações disponibilizadas sobre o Complexo indicam que haveria uma geração relativamente alta de estéril e rejeito (Nicho Engenheiros Consultores Ltda., 2014), ou seja, apesar de economicamente viáveis, as minas operariam com elevados custos e baixa margem operacional.

De certa forma, a decisão da manutenção da operação deste Complexo se deu baseada em uma leitura equivocada do comportamento de preços da Vale no final dos anos 2000. Nesse contexto, a empresa havia proposto o projeto "Barragem Zero", que tinha entre seus objetivos a recuperação do minério nos rejeitos (Franca, 2009). Apesar do baixo teor de ferro presente nos rejeitos dessas barragens, a Vale contava com o investimento em novos sistemas de separação magnética para viabilizar tecnicamente o empreendimento (Brito, 2011).

Se por um lado, com esse projeto, a Vale conseguiria ampliar a vida útil de suas minas e adiar os custos de descomissionamento da parte industrial e remediação ambiental; por outro, a manutenção de cavas quase exauridas, ou mesmo o beneficiamento do rejeito estocado na barragem, exigiria a operação de uma infraestrutura de apoio (barragens, diques e pilhas de estéril) antiga, próxima ao seu limite de capacidade e com elevados custos operacionais. Necessariamente a continuidade das operações desse complexo demandava da Vale investimentos 
significativos em manutenção preventiva para garantir a sua segurança. Todavia, conforme descrito a seguir, esse não parecia ser o cenário no qual o Complexo se encontrava.

\section{As condições de operação do Complexo Paraopeba II}

Como forma de tentar garantir a segurança das barragens de rejeito existentes em Minas Gerais, o governo do estado possui o Programa de Gestão de Barragens de Rejeitos e Resíduos, que sistematiza os resultados dos laudos de segurança elaborados por empresas de auditoria contratada por empresas mineradoras. Esses laudos podem apresentar três conclusões sobre as condições das barragens: aquelas em que o auditor garante que estão estáveis; situações em que, por indisponibilidade de dados, não há conclusão sobre a estabilidade das barragens; e ainda aquelas em que a estabilidade não é garantida.

Nesse sentido, o Complexo Paraopeba II se mostrou um exemplo emblemático das falhas desse sistema de automonitoramento. No caso das barragens de água existentes, as Barragens IV, IVa e Menezes I tiveram repetidamente sua estabilidade não garantida pelo auditor entre os anos os anos 2011 e 2013 (FEAM, 2019). Devido à inação da Vale, e à falta de iniciativa do governo estadual, tal situação somente foi resolvida depois que a Vale foi alvo de Ação Civil Pública, movida pelo Ministério Público (Vale, 2016b)

Para além dos problemas de estabilidade, no passado recente não foram poucas vezes que os auditores identificaram problemas no monitoramento e na manutenção das barragens da Vale no Complexo Paraopeba II.

Por exemplo, em uma fiscalização da Barragem IV, realizada em 2008, o auditor recomendava a implantação de medidas corretivas no sistema de extravasamento, uma vez que se mostrava subdimensionado e corria o risco de transbordamento (Brandt Meio Ambiente, 2014). De forma semelhante, o relatório sobre a Barragem VI apresentado pela Nicho Engenheiros Consultores Ltda. (2010a) recomendava a estabilização de processos erosivos à margem do vertedouro da barragem e uma auditoria mencionada por Brandt

9 Por outro lado, a Barragem I teve sua estabilidade garantida pelo auditor poucos meses antes de romper. Situação semelhante ocorreu com a barragem de Fundão, da Samarco. Essas duas tragédias acabaram por
Meio Ambiente (2014) fazia menção à surgência de água a jusante da barragem. No caso da Barragem VII, o auditor concluiu que o talude de montante se encontrava em situação de instabilidade para a condição de um rebaixamento rápido e recomendava a desativação da barragem. Ele ainda apontava que havia instrumentos de monitoramento previstos que não haviam sido instalados (Brandt Meio Ambiente, 2010). Por fim, nas barragens Menezes I e Menezes II foram identificadas condições inapropriadas de dimensionamento de estruturas hidráulicas e surgência de água (Brandt Meio Ambiente, 2010, 2014).

Apesar de não exaustivos, os aspectos levantados pelas auditorias mostram a regularidade com que problemas operacionais surgiam nas barragens de água que compunham o Complexo Paraopeba II. Isso sugere que procedimentos de monitoramento e manutenção preventiva não eram tratados de forma adequada pela Vale.

Todavia, tal comportamento não se limitava apenas às barragens de água, mas também podia ser identificado em relação à Barragem I. Esta barragem era muito maior do que as demais e, diferente delas, projetada para armazenar rejeitos de mineração. Apesar dessas particularidades, ela também apresentou ao longo de sua história uma série de problemas associados ao seu monitoramento e manutenção.

Antes de detalhar alguns desses aspectos, porém, é importante descrever, mesmo que brevemente, as características construtivas da Barragem I. Isso se deve ao fato de ser uma barragem bastante problemática do ponto de vista estrutural e que, portanto, deveria ter sido objeto de grande atenção e cuidado pela Vale.

A Barragem I foi construída em 1976, com uma altura de $18 \mathrm{~m}$, tendo passado por 10 alteamentos e atingido uma altura final de $86 \mathrm{~m}$. Conforme descrito a seguir, seu histórico apresentou problemas construtivos, que deveriam ter chamado a atenção de auditores e órgãos de fiscalização.

Uma questão importante dessa barragem era referente à heterogeneidade da composição de sua praia de rejeito. As praias consistem em um faixa de

demonstrar a ineficácia do sistema de automonitoramento em vigência no Brasil e a necessidade da construção de um outro sistema efetivamente independente de monitoramento de barragens. 
material criada para reduzir o contato da água armazenada na barragem com o corpo do talude. Para que funcionem adequadamente, essas praias devem ser formadas essencialmente por material de maior granulometria. Todavia, no caso da Barragem I, por quase 30 anos (1976 - 2005) a barragem foi operada sem uma diretriz específica de disposição de rejeito. Como a barragem era do tipo a montante, a praia sobre a qual foram feitos oito dos dez alteamentos não era homogênea e apresentava camadas com diferentes compacidades, umas sendo mais fofas, outras mais compactas. Esta particularidade criava um risco maior da água se acumular na proximidade do talude, podendo comprometer sua estabilidade (Emerman, 2019; Pirete da Silva, 2010; Tüv Süd, 2018).

Além disso, foi identificada durante as auditorias a ausência de documentação referente à construção da barragem. De acordo com Tüv Süd (2018), não foram encontrados registros das investigações geotécnicas referentes ao projeto do maciço inicial, nem documentos referentes às investigações geotécnicas do 4으 e do 5ㅇalteamentos. A ausência de tais documentos dificultava o devido conhecimento das condições dessas estruturas.

Apesar desses problemas terem sido gerados antes da aquisição da Barragem I pela Vale, a empresa tinha conhecimento de sua existência. Portanto, seria de esperar que a companhia tivesse criado protocolos ainda mais rigorosos para seu monitoramento e manutenção preventiva. Todavia, diferentes auditorias mostram que essa não era a situação.

Em 2010, relatórios apontavam a presença de piezômetros danificados, não identificados ou com suspeita de não estarem funcionando corretamente. Nesses documentos, auditores ainda recomendavam a recuperação de drenos e de canais, bem como validação dos estudos existentes sobre liquefação (Brandt Meio Ambiente, 2010; Nicho Engenheiros Consultores Ltda., 2010b). Em outro relatório, publicado quatro anos mais tarde, havia referências a leituras anômalas dos piezômetros, indicação da necessidade de investigações sobre a estrutura da fundação da barragem e das condições de funcionamento do sistema de drenagem interna (Brandt Meio Ambiente, 2014). Um ano depois, outro laudo fazia referência a uma surgência no pé da barragem; e reforçava a necessidade de novas análises sobre a possibilidade de liquefação (Vale, 2015b). Posteriormente, alguns desses problemas continuaram a ser relatados, incluindo o surgimento de trincas no sistema de drenagem e a existência de piezômetros danificados ou inativos (Tüv Süd, 2018).

Dessa forma, o que se percebe é que apesar do conhecimento dos problemas construtivos apresentados pela Barragem I, a Vale não vinha mantendo uma rotina adequada de monitoramento de suas condições e de ações de manutenção preventiva. Em princípio, esse cenário se mostra coerente com um contexto de redução de investimentos em saúde e segurança e uma redução das preocupações com aspectos operacionais da empresa.

\section{Considerações Finais}

Ao longo desse texto nos propusemos a utilizar o modelo das RGPs para analisar as estratégias da Vale e apresentar uma possível interpretação para o surgimento do contexto que permitiu que ocorresse o desastre associado ao rompimento da Barragem I.

A avaliação da rede extrativa na qual a Vale se insere mostra uma empresa muito dependente de um produto (minério de ferro) e um cliente (China) e, por questões, de enraizamento material e em rede (distância do mercado chinês e concentração de seus concorrentes na Austrália), com poder decrescente em relação a seus consumidores e uma baixa capacidade de aumentar sua captura de valor pela venda de seus produtos.

Ao mesmo tempo, mudanças na configuração da empresa associada ao processo de crescente financeirização levaram a um aumento do poder de agentes financeiros em âmbito interno e, consequentemente, maior pressão por retornos crescentes de curto prazo.

Como saída para essa pressão, a empresa lançou mão de suas condições de enraizamento social no Brasil (histórico de empresa estatal, proximidade com agentes públicos e elevado poder econômico) para ampliar sua capacidade de captura de valor a partir das atividades extrativas. Para tanto, campanhas de RSC garantiam sua legitimidade junto à sociedade, enfraquecimento das organizações sindicais reduziam a oposição dos trabalhadores à precarização das condições de trabalho e lobby junto a esferas públicas de forma a fragilizar os sistemas de monitoramento e controle ambiental. Como consequência dessas iniciativas a empresa conseguiu garantir uma redução relativa de seus custos 
operacionais e uma maior disponibilidade de recursos financeiros para serem transferidos aos acionistas.

Todavia, ao mesmo tempo em que ocorriam essas transformações, eram reduzidos também os sistemas de pesos e contrapesos que poderiam garantir que as operações extrativas fossem realizadas em patamares seguros.

Nesse contexto, a continuidade das operações de uma estrutura antiga e vulnerável como a Barragem I se mostrou como a adoção de riscos desproporcionais, que se desdobraram no rompimento da barragem, na morte de 270 pessoas e na destruição do Rio Paraopeba.

Nossa análise, portanto, se propõe a apresentar uma leitura mais ampla do contexto do desastre, que olha para além de Brumadinho e busca identificar aspectos múltiplos que não apenas podem estar associados a esse desastre, mas podem desencadear ainda outros, seja no contexto da Vale, seja no de outras empresas mineradoras. Portanto, a adoção de tal perspectiva sugere que ações preventivas devem olhar para além da questão da segurança de

\section{Referências}

Aguiar, T. T. (2019). O solo movediço da globalização: relações de trabalho na vale S.A. (Doutorado), University de São Paulo,

Anderson, J. E. (2003). Public policymaking: an introduction (5 ed.). Boston; New york: Houghton Mifflin Company.

Angelo, M. (2019, 22 Fev). Vale ditou regras para simplificar licenciamento ambiental em MG. Repórter Brasil. Retrieved from https://reporterbrasil.org.br/2019/02/vale-ditouregras-para-simplificar-licenciamento-ambiental-em$\mathrm{mg} /$

ANM. (2018). Maiores Arrecadadores CFEM. Agência Nacional de Mineração. Retrieved from https://sistemas.dnpm.gov.br/arrecadacao/extra/Relat orios/cfem/maiores_arrecadadores.aspx

Bedinelli, T. (2016, 12 Dez). Os sem-terra desafiam a gigante Vale na Amazônia. El País. Retrieved from https://brasil.elpais.com/brasil/2016/11/23/politica/14 79905291_797076.html

Bertollo, K. (2017). Mineração e superexploração da força de trabalho: análise a partir da realidade de barragens e debater tanto aspectos institucionais, quanto sociais e econômicos do atual modelo mineral brasileiro.

Todavia, essa é uma análise ainda inicial do uso do modelo das RGPs para avalição de redes extrativas no contexto brasileiro. Assim, o presente texto busca sugerir caminhos possíveis para pesquisas futuras. Primeiramente, deve-se considerar que o modelo analítico utilizado se encontra em elaboração, necessitando ainda de aprofundamento e refinamento. Em segundo lugar, coloca-se a necessidade de se avaliar a atuação de outras mineradoras, para compreender o quanto as estratégias aqui identificadas são generalizáveis para as demais empresas do setor, seja no Brasil, seja em outros países. Por fim, cabe reforçar que, embora nossa principal preocupação seja avaliar as estratégias corporativas, outros agentes (movimentos sociais, trabalhadores, Estado, etc.) também atuam de forma ativa na relação com as corporações, devendo o estudo de suas estratégias ser incorporado na agenda de pesquisa sobre RGPS extrativas.

Mariana-MG. (Doutorado), Universidade Federal de Santa Catarina, Florianópolis.

Bhattacharyya, S. S., \& Deepak, P. K. (2012). Comprehending the changing global iron ore trade service system and the dynamics of pricing. International Journal of Business and Globalisation, 9(1), 70-89.

Bourdieu, P. (2005). O campo econômico. Política \& Sociedade, 4(6), 15-58.

Bowker, L. N., \& Chambers, D. M. (2017). In the dark shadow of the supercycle tailings failure risk \& public liability reach all time highs. Environments, 4(75), 1-21.

Brandt Meio Ambiente. (2010). Mina Córrego do Feijão - Relatório de Avaliação de Desempenho Ambiental (RADA). Retrieved from Belo Horizonte:

Brandt Meio Ambiente. (2014). Mina da Jangada e Mina Córrego do Feijão - Relatório de Avaliação de Desempenho Ambiental (RADA). Retrieved from Belo Horizonte:

Brito, A. (2011, 23 Ago). Minério em alta faz Vale investir em recuperar toneladas de rejeito. Folha $S$. Paulo. Retrieved from https://www1.folha.uol.com.br/fsp/mercado/me23082 01130.htm 
Campos, C. M. (2015). As práticas empresariais à luz da Justiça ambiental: análise de um conflito entre água e mineração em Brumadinho, Minas Gerais, de 2011 a 2015. (MBA), Fundação Getúlio vargas, Belo Horizonte.

Coe, N. M., Dicken, P., \& Hess, M. (2008). Global production networks: realizing the potential. Journal of Economic Geography, 8(3), 271-295.

Coe, N. M., Lai, K. P., \& Wójcik, D. (2014). Integrating finance into global production networks. Regional Studies, 48(5), 761-777.

Coe, N. M., \& Yeung, H. W.-C. (2015). Global Production Networks: theorizing economic development in an interconnected world. New York: Oxford University Press.

Coelho, T. P., Milanez, B., \& Pinto, R. G. (2016). A empresa, o Estado e as comunidades. In M. Zonta \& C. Trocate (Eds.), Antes fosse mais leve a carga: reflexões sobre o desastre da Samarco / Vale / BHP Billiton (pp. 183-227). Marabá: Editorial iGuana.

Cox, K. R. (1998). Spaces of dependence, spaces of engagement and the politics of scale, or: looking for local politics. Political geography, 17(1), 1-23.

Davies, M., \& Martin, T. (2009). Mining Market Cycles and Tailings Dam Incidents. Paper presented at the 13th International Conference on Tailings and Mine Waste, Banff,

$A B$.

http://www.infomine.com/publications/docs/Davies2009. pdf

Dicken, P. (2011). Global shift: mapping the changing contours of the world economy. New York: The Guilford Press.

Domenici, T. (2017, 23 Nov). Estrada de ferro Carajás: Processados pela Vale. Agência Pública. Retrieved from https://apublica.org/2017/11/processados-pela-vale/

Dörry, S. (2016). The geographies of industrialised finance: probing the Global Production Networks of Asset Management. Geography Compass, 10, 3-14.

Dye, T. R. (2013). Understanding public polic (14 ed.). Saddle River: Pearson Education, Inc.

Emerman, S. H. (2019). English-language summary of a 2010 Master's thesis on the stability of the failed dam at the Córrego do Feijão Mine. Retrieved from Spanish Fork, UT:

ESMAP, Mundial, B., \& ICMM. (2005). Toolkit. Ferramentes para Desenvolvimento de Comunidades. Versão Preliminar. Retrieved from http://www.ibram.org.br/sites/1300/1382/00000087.pdf
FEAM. (2019, 08 Fev). Gestão de barragens. Fundação Estadual do Meio Ambiente. Retrieved from http://www.feam.br/monitoramento/gestao-debarragens

Felippe, M. F. (2019). [Comunicação pessoal. Relato de campo].

Fligstein, N. (2002). The architecture of markets: An economic sociology of twenty-first-century capitalist societies: Princeton University Press.

Franca, P. (2009). Projetos de disposição de rejeitos na Vale: diversidade de soluções, riscos e desafios. Paper presented at the 130 Congresso Brasileiro de Mineração, Belo Horizonte. http://www.ibram.org.br/sites/1300/1382/00000551.p df

Fuchs, D. (2013). Theorizing the power of global companies. In J. Mikler (Ed.), The handbook of global companies (pp. 77-95). West Sussex: John Wiley \& Sons.

Gereffi, G. (1994). The Organization of buyer-driven global commodity chains: How U.S. retailers shape overseas production networks. In G. Gereffi \& M. Korzeniewicz (Eds.), Commodity chains and global capitalism. Westport: Praeger.

Gereffi, G., Humphrey, J., \& Sturgeon, T. (2005). The governance of global value chains. Review of International Political Economy, 12(1), 78-104.

Giffoni Pinto, R. (2015). Dos riscos das políticas às políticas do risco: um estudo sobre os "riscos sociais corporativos" e suas formas de gestão. (Doutorado), Universidade Federal do Rio de Janeiro, Rio de Janeiro.

Granovetter, M. (2007). Ação econômica e estrutura social: o problema da imersão. RAE Eletrônica, 6(1), 141.

Henderson, J., Dicken, P., Hess, M., Coe, N. M., \& Yeung, H. W.-C. (2002). Global production networks and the analysis of economic development. Review of International Political Economy, 9(3), 436-464.

Hess, M. (2004). 'Spatial relationships? Towards a reconceptualization of embeddedness. Progress in Human Geography, 28(2), 165-186.

INESC. (2017, 28 Nov). Vale no centro do conflito de terra em Canaã dos Carajás. Retrieved from http://amazonia.inesc.org.br/materias/vale-no-centrodo-conflito-de-terra-em-canaa-dos-carajas/

International Trade Center. (2019). Trade map: trade statistics for international business development. Retrieved from http://www.trademap.org 
Kaplinsky, R. (1998). Globalisation, industrialisation, and sustainable growth: the pursuit of the Nth rent (365). Retrieved from Brighton

Löf, A., \& Ericsson, M. (2016). Iron Ore Market Report 2016. Engineering and Mining Journal, 217(11), 22-26.

Löf, A., \& Ericsson, M. (2017). Iron Ore Market Report 2017. Engineering and Mining Journal, 218(11), 32-37.

Ma, Y. (2013). Iron ore spot price volatility and change in forward pricing mechanism. Resources Policy, 38(4), 621-627.

Mansur, M., Wanderley, L. J. M., Milanez, B., Santos, R. S. P., Pinto, R. G., Gonçalves, R. J. A. F., \& Coelho, T. P. (2016). Antes fosse mais leve a carga: introdução aos argumentos e recomendações referentes ao desastre da Samarco / Vale / BHP Billiton. In M. Zonta \& C. Trocate (Eds.), Antes fosse mais leve a carga: reflexões sobre o desastre da Samarco / Vale / BHP Billiton (pp. 17-49). Marabá: Editorial iGuana.

Market index. (2018). Iron Ore 37yr price history. Market index, Retrieved from https://www.marketindex.com.au/sites/default/files/c ommodities/iron-ore-price-history.xlsx

Milanez, B., Coelho, T. P., \& Wanderley, L. J. M. (2017). O projeto mineral no Governo Temer: menos Estado, mais mercado. Versos - Textos para Discussão PoEMAS, 1(2), 1-15.

Milanez, B., Magno, L., Santos, R. S. P., Coelho, T. P., Giffoni Pinto, R., Wanderley, L. J. M., .. . Gonçalves, R. J. A. F. (2019). Minas não há mais: avaliação dos aspectos econômicos e institucionais do desastre da Vale na bacia do rio Paraopeba. Versos - Textos para Discussão POEMAS, 3(1), 1-114.

Milanez, B., Santos, R. S. P., Magno, L., Wanderley, L. J. M., Mansur, M. S., Giffoni Pinto, R., . . Coelho, T. P. (2018). A Estratégia Corporativa da Vale S.A.: um modelo analítico para Redes Globais Extrativas. Versos - Textos para Discussão PoEMAS, 2(2), 1-43. doi:10.13140/RG.2.2.17430.60483

Mintzberg, H. (1987). The strategy concept I: five Ps for strategy. California Management Review, 30(1), 1134.

MME. (2011). Plano Nacional de Mineração 2030. Brasília: Ministério de Minas e Energia, Secretaria de Geologia, Mineração e Transformação Mineral.

Nicho Engenheiros Consultores Ltda. (2010a). Mina Córrego do Feijão recuperação de pellet feed da barragem I e VI e estruturas associadas - Estudo de Impacto Ambiental (EIA). Brumadinho.

Nicho Engenheiros Consultores Ltda. (2010b). Mina Córrego do Feijão recuperação de pellet feed da barragem I e VI e estruturas associadas - Plano de Controle Ambiental (PCA). Brumadinho.

Nicho Engenheiros Consultores Ltda. (2014). Mina da Jangada - continuidade das operações da mina da Jangada - Estudo de Impacto Ambiental e Plano de Controle Ambiental EIA/PCA Tomo I. Belo Horizonte.

Oliveira, C. R. (2013). Quem é quem nas discussões do novo código da mineração. Rio de Janeiro: IBASE.

Oliveira, C. R. (2015). Quem é quem nas discussões do novo código da mineração 2014 Rio de Janeiro: IBASE.

Pirete da Silva, W. (2010). Estudo do potencial de liquefação estática de uma barragem de rejeito alteada para montante aplicando a metodologia de Olson (2001). (Mestrado Profissional), Universidade Federal de Ouro Preto, Ouro Preto.

Possato, V., Zuba, F., \& Andrade, N. (2019, 27 Mai). Brumadinho: terrenos atingidos pela lama da Vale têm potencial de mineração. G1. Retrieved from https://g1.globo.com/mg/minasgerais/noticia/2019/05/27/brumadinho-terrenosatingidos-pela-lama-da-vale-tem-potencial-demineracao.ghtml

Ramalho, J. R., \& Santos, R. S. P. (2018). Trabalho e ação sindical em Redes Globais de Produção. Tempo Social, 30(1), 9-29.

Rehner, J. (2012). Territorios corporativos: Una reflexión desde la geografía económica para evitar la axiomatización de los discursos. Espacios, 2(4), 27-42.

Santos, R. S. P. (2010). A forja de Vulcano: siderurgia e desenvolvimento na Amazônia Oriental e no Rio de Janeiro. (Ph.D.), Universidade Federal do Rio de Janeiro, Rio de Janeiro.

Santos, R. S. P. (2011). Redes de produção globais (RPGs): contribuições conceituais para a pesquisa em ciências sociais. Revista Pós Ciências Sociais, 8(15), 127141.

Santos, R. S. P. (2016). Análise de Conjuntura: boom e pós-boom da mineração. Paper presented at the Seminário 'Modelo de Extrativismo Mineral sob Crítica', Vitória (ES).

Santos, R. S. P. (2017). A nova governança corporativa da Vale S.A.: um percurso político em direção à "true corporation". Versos - Textos para Discussão PoEMAS, 1(4), 1-20. 
Santos, R. S. P., \& Milanez, B. (2015a). Redes Globais de Produção (RGPS) e conflito socioambiental: A Vale $S A$ e o complexo minerário de Itabira. Paper presented at the VII Simpósio Internacional de Geografia Agrária, Goiânia.

Santos, R. S. P., \& Milanez, B. (2015b). A RGP da Anglo American e conflitos socioambientais na mineração de ferro: valor, poder e enraizamento no Projeto Minas-Rio. Paper presented at the 390 Encontro Anual da ANPOCS, Caxambu, MG.

Santos, R. S. P., \& Milanez, B. (2017). Estratégias corporativas no setor extrativo: uma agenda de pesquisa para as Ciências Sociais. Caderno Eletrônico de Ciências Sociais, 5(1), 01-26.

Santos, R. S. P., \& Wanderley, L. J. M. (2016). Dependência de barragem, alternativas tecnológicas e a inação do estado: repercussões sobre o monitoramento de barragens e o licenciamento do Fundão. In M. Zonta \& C. Trocate (Eds.), Antes fosse mais leve a carga: reflexões sobre o desastre da Samarco / Vale / BHP (Vol. 2, pp. 87137). Marabá: Editorial Iguana.

SICONFI. (2018). Consultar Declaração. Sistema de Informações Contábeis e Fiscais do Setor Público Brasileiro. Retrieved from https://siconfi.tesouro.gov.br/siconfi/pages/public/dec laracao/declaracao_list.jsf;jsessionid=uqR1rIUadzbSJK5 xsKBDdguk.node1

Silva, M. Z. (2004). A Vale do Rio Doce na estratégia do desenvolvimentismo brasileiro. Vitória: EDUFES.

Silveira, M. L. (2007). Los territorios corporativos de la globalización. Geograficando, 3(3).

Sukagawa, P. (2010). Is iron ore priced as a commodity? Past and current practice. Resources Policy, 35(1), 54-63.

Szablowski, D. (2007). Transnational law and local struggles: mining, communities and the World Bank. Oxford and Portland, Oregon: Hart Publishing.

Triner, G. D. (2011). Mining and the state in Brazilian development. London: Pickering \& Chatto.

Tüv Süd. (2018). Revisão periódica de segurança de barragem mina Córrego Feijão - Barragem I - Relatório técnico. Retrieved from

União, Instituto Brasileiro de Meio Ambiente e dos Recursos Naturais Renováveis, Instituto Chico Mendes de Conservação da Biodiversidade, Agência Nacional de Águas, Departamento Nacional de Produção Mineral, Fundação Nacional do Índio, . . . BHP Billiton Brasil Ltda. (2016). Termo de Transação e de Ajustamento de Conduta. Brasília.
Vale. (2011, 28 Abr). Formulário 20-F. Relatório Anual 2010. Retrieved from http://www.vale.com/PT/investors/informationmarket/annual-reports/20f/20FDocs/20F_2010_p.pdf

Vale. (2015a). Formulário de Referência 2015. Rio de Janeiro: Vale S.A.

Vale. (2015b). GARAL 644/2015 Ref PA COPAM 245/2004/046/2010 - Rev. LO 211/2011 - Revalidação Mina Córrego do Feijão. Nova Lima: Vale S.A.

Vale. (2016a). Formulário de Referência 2016. Rio de Janeiro: Vale S.A.

Vale. (2016b). Mina da Jangada e Mina Córrego do Feijão - Relatório de Avaliação de Desempenho Ambiental - RADA. Belo Horizonte: Vale S.A.

Vale. (2017a, $10 \mathrm{Abr}$ ). Formulário 20-F. Relatório Anual 2016. Retrieved from http://www.vale.com/PT/investors/informationmarket/annual-reports/20f/20FDocs/Vale_20F_FY2016_-_p.pdf

Vale. (2017b). Formulário de Referência 2017. Rio de Janeiro: Vale S.A.

Vale. (2017c). Produção e vendas da Vale no 4T16. Rio de Janeiro: Vale S.A.

Vale. (2018a). Demonstrações Financeiras 31 de dezembro de 2017. IFRS em US\$̦(Português). Retrieved from Rio de Janeiro: http://www.vale.com/PT/investors/informationmarket/quarterlyresults/ResultadosTrimestrais/vale_IFRs_BRL_3T18p.pdf

Vale. (2018b, 13 Abr). Formulário 20-F. Relatório Anual 2017. Retrieved from http://www.vale.com/EN/investors/informationmarket/annualreports/20f/20FDocs/Vale_20F_2017_i.PDF

Vale. (2018c). Formulário de Referência 2018. Rio de Janeiro: Vale S.A.

Vale. (2018d). Relatório da Administração. Desempenho da Vale em 2017. Retrieved from Rio de Janeiro: http://www.vale.com/PT/investors/informationmarket/quarterly-

results/ResultadosTrimestrais/RELATORIO\%20DA\%20AD MINISTRACAO\%202017.pdf

Vale. (2018e). Relatório de Sustentabilidade 2017. Rio de Janeiro.

Vale. (2019a). Demonstrações Financeiras 31 de dezembro de 2018. IFRS em US\$̦(Português). Retrieved from Rio de Janeiro: http://www.vale.com/PT/investors/information- 
market/quarterly-

results/ResultadosTrimestrais/vale_IFRs_BRL_3T18p.pdf

Vale. (2019b, 13 Abr). Formulário 20-F. Relatório Anual 2018. Retrieved from http://www.vale.com/PT/investors/informationmarket/annual-reports/20f/20FDocs/Vale_20F\%20FY2018\%20-\%20final_p.pdf

Vale. (2019c). Produção e vendas da Vale no 4T18. Rio de Janeiro: Vale S.A.

Vale. (2019d). Relatório de Sustentabilidade 2018. Rio de Janeiro: Vale S.A.

Valor Econômico. (2015, 16 Mar 2015). Vale é autuada por manter pessoas em condição análoga a de escravo. Retrieved from https://www.valor.com.br/brasil/3956532/vale-eautuada-por-manter-pessoas-em-condicao-analogade-escravo

Wainberg, R. (2017, 12 Dez). O que são debêntures? Pergunta muito comum no mercado financeiro. Suno Research. Retrieved from https://www.sunoresearch.com.br/artigos/o-que-saodebentures/

\section{Sobre os Autores}

- Bruno Milanez, - Universidade Federal de Juíz de Fora - UFJF, Minas Gerais, (Brasil). E-mail: bruno.milanez@ufjf.edu.br Orcid id: https://orcid.org/0000-0002-5330-7407

- Rodrigo Salles Pereira dos Santos - Universidade Federal do Rio de Janeiro - UFRJ, Rio de Janeiro, (Brasil). E-mail: santosrodrigosp@googlemail.com

- Maíra Sertã Mansur - Universidade Federal do Rio de Janeiro - UFRJ, Rio de Janeiro, (Brasil). E-mail: anadido@gmail.com Orcid id: https://orcid.org/0000-0002-2833-813X

- Tádzio Peters Coelho - Universidade Federal do Maranhão - UFMA - Maranhã, (Brasil). E-mail: tadzioguaiabera@gmail.com Orcid id: https://orcid.org/0000-0001-8770-8893 


\title{
TRACKING LINKS TO A DISASTER: POWER AND STRATEGY IN VALE'S GLOBAL PRODUCTION NETWORK
}

\author{
Bruno Milanez, Rodrigo Salles Pereira dos Santos, Maíra Sertã Mansur, Tádzio Peters Coelho \\ Universidade Federal do Rio de Janeiro - UFRJ, Rio de Janeiro, (Brasil) \\ Universidade Federal de Juíz de Fora - UFJF, Minas Gerais, (Brasil) \\ Universidade Federal do Maranhão - UFMA - Maranhão, (Brasil)
}

\begin{tabular}{|c|}
\hline ARTICLE DETAILS \\
\hline $\begin{array}{l}\text { Article History: } \\
\text { Guest Article } \\
\text { Available online August: } 01 \text { th } 2019\end{array}$ \\
\hline $\begin{array}{l}\text { Scientific Editor } \\
\text { Ilan Avrichir }\end{array}$ \\
\hline $\begin{array}{l}\text { Keywords } \\
\text { Global Production Networks (GPNs) } \\
\text { Iron Ore } \\
\text { Tailings Dam }\end{array}$ \\
\hline
\end{tabular}

\begin{abstract}
Grounded on the Global Production Network framework, we argue that elements that resulted in the failure of Dam I, property of Vale S.A. in Brumadinho (MG), in 2019, can be interpreted using the companies exercise of power, which nullified the existing systems of checks and balances, and the value capture, through reduction of operational costs, in order to increase the payment to shareholders, in a context of increasing financialisation. The article is based on literature review and document analysis. The argument is presented using the concept of strategy, which is defined as a repertoire of coordinated actions performed by one or more actors and involves the exercise of power aiming at: (1) increase its capacity to enhance or capture value; (2) expand its power or reduce the power of other actors and/or (3) changes the conditions of embeddedness. Using such a definition, then we analyse the opportunities and constraints towards value creation and capture by Vale and relate its strategies to the increasing operational risks of Dam I.
\end{abstract}

\section{Para citar este artigo:}

Milanez, B., dos Santos, R., Mansur, M., \& Coelho, T. (2019). Buscando Conexões para o Desastre: Poder e Estratégia na Rede Global de Produção da Vale. Internext, 14(3), 265-285. doi:http://dx.doi.org/10.18568/internext.v14i3.561 